\title{
One-fourth of the World's Plant and Animal Species May Face Extinction
}

An international campaign aimed at stopping the greatest extinction of plants and animals since the dinosaurs disappeared some 65 million years ago is being launched by the World Resources Institute, United Nations Environment Programme, and the World Conservation Union (IUCN). These organizations, with headquarters in the United States, Kenya, and Switzerland, respectively, have formed a unique partnership to mobilize scientific and conservation leaders around the world to produce a global strategy and action plan to halt the destruction of the Earth's biological diversity and genetic heritage.

A new report, Keeping Options Alive, and accompanying survey of research and conservation activities, released by the World Resources Institute, shows that $25 \%$ of the world's plant and animal species face extinction within the next 25-50 years if current rates of loss continue. Yet total US funding for programmes to conserve biodiversity in developing countries was only $\$ 37.5$ millions in 1987 -less than $1 \%$ of what Americans spend every year going to the movies!

'As the 21 st century approaches, the world is being deprived of its most fundamental capital stock - its species, habitats, and ecosystems,' explains James Gustave Speth, President of the World Resources Institute. 'The impact of such losses on human well-being is potentially devastating. No longer is it acceptable merely to slow the rate of destruction. We must bring biotic impoverishment to a halt.'

\section{Campaign Starting Immediately}

The united campaign is beginning with consultations in Bangkok, Thailand, followed by a session in the Amazon Basin. Consultations will be held on nearly every continent. The World Resources Institute will seek extensive involvement from community and tribal leaders, nongovernmental organizations, government officials, and international representatives around the world. The focus will be on a critical examination of the underlying causes of rapid species and habitat losses, and formulation of a global strategy and action-plan to halt the destruction. The final strategy and action plans will be presented to participants in a major global conference to be hosted in 1992 by the United Nations.

The World Resources Institute report was prepared by Dr Walter V. Reid, WRI associate, and Dr Kenton R. Miller, head of WRI's Program in Forests and Biodiversity. It dramatically describes the alarming loss of biodiversity - the mix of plants, animals, and natural habitats, that provide vital food, medicine, agricultural products, chemicals, and other resources. The rate of extinctions of birds and mammals may be as much as 100 to 1000 times as high as it would be if Nature were undisturbed by human intervention. Destruction of tropical forests is the single greatest cause of species extinction. From 15.000 to 50,000 species per year, or 50 to 150 species per day, may be lost over the next half-century if deforestation rates continue unabated.

\section{Critical Loss of Biodiversity}

The biodiversity crisis is not restricted to tropical forests but affects other terrestrial and marine areas throughout the world. In the Florida Everglades, for example, endangered taxa such as the Florida panther (Felix concolor coryi) and the Wood Stork (Mycteria americana) are close to ex- tinction because of pollution and Man-made changes in the water drainage. Ancient forests in the Pacific Northwest and Alaska - rich in species of birds, amphibians, flowering plants, and mushrooms, that are found nowhere else in the world-are being destroyed by questionable logging practices. Oceanic archipelagos such as those of Hawaii, the Galápagos, and Canary Islands, are among the most threatened ecological systems on Earth.

In recent months, the effort to save elephants from extinction has become the symbolic battleground against humanity's destructive ways. Poachers have slaughtered nearly $50 \%$ of the remaining African Elephants (Loxodonta africana) for ivory - one is killed on the average every ten minutes. Conservationists predict that, if the killing continues, the African Elephant could disappear from the wild in the next decade.

There is growing recognition that biodiversity is central to basic human needs. Much in agriculture depends on wild genetic resources and biological controls; medicine draws on Nature for pharmaceuticals; industry requires raw materials; tourism increasingly bases its attractions on natural settings; many fisheries depend on swamp forests and mangroves as nursery grounds; and disaster prevention relies on natural vegetation to prevent landslides and floods.

\section{Research Backing Inadequate But Due to Improve}

Yet resources spent on biodiversity research and conservation are minimal in relation to the enormity of the problem. According to a survey of US-based efforts in developing countries by a WRI Research Analyst. US-based institutions spent only $\$ 37.5$ millions for 873 projects in 86 countries in 1987. More than half of these funds went to projects in Latin America and the Caribbean; 16\% to Asia: $12 \%$ to Africa; and $11 \%$ for global or multi-regional projects. More than $40 \%$ of the funds were for research, while $23 \%$ were used for protected areas.

Conservationists strongly praise efforts by zoos, parks. botanical gardens, seed collection centres, and others, to rescue and propagate endangered species and educate the public to the problems. But the losses have become so great, so rapid, and so critical, that a massive, intense, international reordering of social, economic, and political, priorities is needed.

The World Resources Institute, UN Environment Programme, and World Conservation Union, have already gained commitments from a variety of valued collaborating agencies including the World Bank, World Wildlife Fund, Asian Development Bank, Conservation International, Missouri Botanical Garden, African Non-governmental Environment Network, Costa Rica's Fundacion Neotropica and Fundacion de Parques Nacionales, Ecuador's Fundacion Natura, Center for Marine Conservation. Society for Conservation Biology. World Conservation Monitoring Centre, International Council for Bird Preservation, and Eastern Caribbean Natural Areas Management Program. They are also working closely with the Food and Agriculture Organization of the United Nations and the United Nations Education, Science and Cultural Organization on the project.

Shirley GeER

World Resources Institute 1709 New York Avenue, NW Washington DC 20006, USA. 